J Gastrointest Cancer. 2013 March ; 44(1): 46-53. doi:10.1007/s12029-012-9455-5.

\title{
Burden of Emergency and Non-emergency Colorectal Cancer Surgeries in West Virginia and the USA
}

\author{
Neel A. Shah, Joel Halverson, and Suresh Madhavan \\ Department of Pharmaceutical Systems and Policy, School of Pharmacy, West Virginia University, \\ Morgantown, WV 26506-9510, USA \\ Neel A. Shah: nshah@hsc.wvu.edu
}

\begin{abstract}
Purpose-Elective surgical resection is the curative treatment for colorectal cancer (CRC). Up to $30 \%$ of patients present as surgical emergencies. The objective was to determine the association between presenting with an emergency condition and consequent outcomes of CRC surgery in the Appalachian state of West Virginia (WV) in comparison to the rest of the USA.
\end{abstract}

Methods-Patients diagnosed with CRC who underwent a surgical procedure from January 1, 2003 to December 31, 2007 were selected, and those with a diagnosis requiring emergency surgery were identified. Primary outcome measures were length of stay (LOS), total hospital charges, and inpatient death.

Results-Mean LOS was higher for WV. Mean charges were higher for the USA than for WV. Inpatient deaths in WV were greater than the rest of the USA. Those undergoing emergency surgery spent $51.9 \%(\beta=0.40)$ more days in the hospital than those who did not. For WV, LOS was $7.6 \%(\beta=0.07)$ higher than that of the US. Hospital charges for those that underwent emergency resection were $68.3 \%(\beta=0.52)$ higher than those who did not. The odds of in-hospital death were 1.68 (95\% CI=1.42-1.98) times greater in WV than in the USA. Those that underwent emergency surgery had a nearly four times (OR 3.88; $95 \% \mathrm{CI}=3.74-4.03)$ greater chance of inhospital death.

Conclusions-The study stresses the ongoing burden of emergency surgeries in many states around the nation and the need to increase awareness about CRC screening practices, especially in patients who are at increased risk of the disease.

\section{Keywords}

Colorectal cancer; Emergency surgery; Inpatient death; Length of stay; Total charges; Screening

Correspondence to: Neel A. Shah, nshah@hsc. wvu. edu.

Disclosure

The content is solely the responsibility of the authors and does not necessarily represent the official views of the Agency for Healthcare Research and Quality. The authors claim no conflicts of interest. At the time the study was conducted, manuscript written, and sent for initial review, Neel A. Shah was a graduate student and PhD candidate at West Virginia University, School of Pharmacy, Morgantown, WV. At the time of acceptance and publication, Neel A. Shah was an employee of Amgen, Inc., Thousand Oaks, CA. 


\section{Introduction}

The incidence and mortality from colorectal cancer (CRC) are decreasing significantly due to increasing screening rates; however, disparities in screening, treatment, and survival persist [ $\left.{ }^{1}{ }^{4}\right]$. In 2011, approximately 141,210 men and women were expected to be diagnosed and approximately 49,380 are expected to succumb to CRC [ $\left.{ }^{5}\right]$. Screening for CRC can identify polyps or abnormal growths before they turn cancerous. Timely screening can lead to early detection of the cancer, better prognosis of the disease, and, finally, improved observed survival rates $\left.{ }^{6}\right]$.

Typically, resection of the tumor plus the surrounding areas of cancerous and non-cancerous colon and regional lymph nodes is the most effective treatment $\left.{ }^{7}\right]$. Although elective surgical resection is the curative treatment for CRC, up to $30 \%$ of patients present as surgical emergencies [ ${ }^{8}{ }^{12}$ ]. Clinical presentation necessitating emergency CRC resection has been identified as strong evidence at an individual level for a failure of screening, resulting from factors such as inadequate access to care or underutilization of cancer screening services and contributing to the disparities in CRC outcomes [ $\left.{ }^{12},{ }^{13}\right]$.

Although previous studies have attempted to establish a link between delayed diagnosis due to poor screening practices and presenting emergently with CRC, there is a lack of sufficient evidence associating emergency surgery with hospital-related outcomes. Any previous evidence is primarily limited to single-community hospitals $[10,12,14]$. In addition to the burden of morbidity and mortality, the economic burden of treatment and prognosis is also significant. Since surgery is usually performed immediately following a diagnosis for CRC, the cost of this and the required hospitalization constitute approximately $80 \%$ of total direct costs $\left[{ }^{7}\right]$. Therefore, this study was conducted to determine the association between presenting with an emergency condition and consequent outcomes of CRC surgery in greater detail in the Appalachian state of West Virginia, which ranks number one in both incident cases and mortality rates for CRC in the USA. West Virginia is an excellent example for such a study given the other states in the region with high CRC incidence and mortality rates such as Kentucky and Pennsylvania.

West Virginia is the only Appalachian state that is situated entirely in Appalachia [ $\left.{ }^{15}\right]$. The US Department of Health and Human Services considers the rural residents of Appalachia a "special population" $\left.{ }^{16}\right]$. These residents tend to be older, poorer, less educated, and more likely to be uninsured than urban Americans. More than half (53.9\%) of West Virginians live in rural areas and $18.9 \%$ have no usual source of health care coverage, which makes access to care challenging for a large part of the population $\left[{ }^{17}\right]$. In 2000, West Virginia passed legislation that prohibits insurers from denying reimbursement for CRC screening for any non-symptomatic person over age 50 and any symptomatic person under age 50 [ $\left.{ }^{18}\right]$. Despite this legislation, screening rates for CRC among West Virginians remain the lowest in the USA [ ${ }^{19}$ ], and between 2003 and 2007 West Virginia had the highest incidence as well as mortality from CRC of all the 50 states in non-Hispanic White men and women [ $\left.{ }^{5}\right]$. The state's leading rank in CRC incidence and mortality has remained unchanged since the rates reported for the years 2001 to 2005 by the same organization $\left[{ }^{20}\right]$. 
The aims of the study were to:

1. Describe and compare the characteristics of patients undergoing surgery for CRC from Jan 1, 2003 to Dec 31, 2007 in both the West Virginia State Inpatient Database (SID) and the Nationwide Inpatient Sample (NIS)

2. Determine the differences in emergency and non-emergency CRC surgery in West Virginia and the national sample

3. Compare the differences in length of stay (LOS), total hospital charges, and inhospital death between West Virginia and the national sample in emergency and non-emergency surgery cases

\section{Methods}

This cross-sectional comparison of a national sample to West Virginia CRC hospitalizations was conducted using the NIS data and the West Virginia SID from 2003 to 2007 of the Healthcare Cost and Utilization Project (HCUP) of the Agency for Healthcare Research and Quality. The NIS is designed to approximate a 20-\% sample of US community hospitals. All numbers for the NIS are weighted to produce national estimates. The discharge weights are calculated for NIS data by firstly stratifying the NIS hospitals on the same variables that were used for creating the sample. These variables are geographic region (state), urban/rural location, teaching status, bed size, and ownership. A weight is then calculated for each stratum by dividing the number of universe discharges in that stratum-obtained from American Hospital Association data—by the number of NIS discharges in the stratum. Weighted estimates are calculated by uniformly applying stratum weights to the discharges according to the stratum from which the discharge was drawn. Weights have been assigned to each discharge and are stored in each record in the data element DISCWT. When the discharge weights are applied to the unweighted NIS data, the result is an estimate of the number of discharges for the entire universe. In the case of the NIS, the universe is all inpatient discharges from community hospitals in the USA.

From 2003 to 2007, the NIS has data ranging from 37 to 40 states with weighted discharges representative of the US population, ranging from 38,220,659 in 2003 to 39,541,948 in 2007. The WV SID contains the universe of West Virginia's hospital inpatient discharge records. The SID discharges range from 288,084 to 295,613 between 2003 and 2007. To avoid overlap and duplication, only discharges that were not from WV hospitals were included in the NIS data for this study.

\section{Study Cohorts}

To create a cohort of patients who underwent CRC surgery, first, the International Classification of Diseases, Ninth Revision, Clinical Modification (ICD-9-CM) codes for $\mathrm{CRC}$ in any of nine diagnosis fields for the 5 years were used to identify hospitalized patients ( $N=9,424$ for SID and $N=1,115,454$ for NIS). This includes diagnosis codes for malignant neoplasms of the colon (codes 153.0-9) and rectum (codes 154.0-1) $\left.{ }^{13}\right]$. After CRC discharges for all 5 years were combined for both data sets, a subset of patients who underwent surgical procedures ( $N=3,338$ for SID and $N=513,177$ for NIS) in the colon and 
rectum were identified using ICD-9-CM procedure codes for colon resection (codes $45.7 \times$ and 45.8), rectal resection (codes 48.4x, 48.5, 48.6x), and other operations on the intestine including colostomy and ileostomy (codes 46.1-2) [ $\left.{ }^{13}, 21,22\right]$. From these patients, a final subset presenting with a diagnosis requiring emergency surgery, including bowel perforation, peritonitis, or obstruction, was identified ( $N=277$ for SID and $N=54,420$ for NIS). The ICD-9-CM diagnosis codes used to determine which patients met these criteria included other specified intestinal obstruction (code 560.8), unspecified intestinal obstruction (code 560.9), peritonitis in infectious diseases (code 567.0), other suppurative peritonitis (code 567.2), other specified peritonitis (code 567.8), unspecified peritonitis (code 567.9), and perforation of the intestine (code 569.83). Cell sizes less than 11 were hidden to protect patients from being identified. Any cell with $N$ of less than 11 is prohibited from being disclosed as required by HCUP.

\section{Variables of Interest}

Variables available in both datasets included age, sex, primary payer (insurance status), and presence of comorbidities. Two thirds of all new cases of CRC occur in individuals over the age of 65, a large segment of which are covered by Medicare $\left[{ }^{23}\right]$. Guidelines recommend CRC screening for average-risk adults beginning between ages 40 and 50 depending on race $\left.{ }^{24}\right]$. Therefore, for this study, age was categorized into age groups as less than 65 years and as 65 years and over. This segregation takes into account differences in insurance status, variations in healthcare utilization, and disparities in screening and treatment for CRC. Race in the NIS was categorized as White, Black, Hispanic, and other. Primary payer as provided by datasets is categorized as Medicare, Medicaid, private, self-pay, no charge, and other. For this study, the self-pay and no charge were collapsed into the category "other" to yield a total of four categories for insurance status. Comorbidities were identified using the method developed by Elixhauser and colleagues $\left[{ }^{25}\right]$. This method retains comorbidities as separate, independent measures because individual comorbidities may be irrelevant for some diseases but may influence the outcomes of different diseases and treatments in different ways $\left[{ }^{25}\right]$. This is especially true for specific diseases like diabetes, obesity, and chronic heart failure that are known to influence the incidence, prognosis, as well as the outcome of CRC [ ${ }^{26}$ 28 ]. Therefore, three most common chronic comorbid conditions in the West Virginia and NIS cohorts not associated with cancer were identified, and each was treated as a separate independent variable.

The outcome variables of interest in this study were inhospital LOS, hospital charges, and in-hospital death due to CRC. LOS was defined as the difference in the number of days between the first date and the last date of hospitalization. Because actual costs as well as the amount reimbursed by the payer were unavailable, hospital charges were used to represent financial burden. If the patient died during hospital stay, it was indicated accordingly in each discharge record.

\section{Statistical Analyses}

Descriptive analyses using chi-square statistic were performed, comparing emergency and non-emergency conditions for CRC resection for both the SID and NIS cohorts with the variables available for each cohort. The West Virginia cohort was then merged with the 
weighted cases of the NIS. The West Virginia data were population data and therefore these cases were given a weight of 1 . Next, a dummy variable "state" was created, which was used to compare West Virginia with the other states in the NIS.

Multivariate regressions investigated differences in the log-transformed LOS and logtransformed total hospital charges between the West Virginia and NIS cohorts after controlling for surgery. The effect of dummy variables in terms of percentage of the logtransformed outcomes can be estimated by exponentiating the regression coefficients of dummy variables and subtracting 1 (i.e., percent change $=e^{\beta}-1$ ) $\left[{ }^{29}\right]$. Similarly, binary logistic regressions were conducted to compare in-hospital deaths between the West Virginia and NIS cohorts. All data were extracted and analyzed using SAS version 9.2 and IBM SPSS version 20.

\section{Results}

Descriptions of the patients by type of surgery in West Virginia and the USA are summarized. In West Virginia (Table 1), the percentage of people that presented as an emergency condition for surgery versus non-emergently was similar across all groups within each patient characteristic. In the US sample, statistically significant differences were seen within race groups, insurance status, and number of comorbidities (Table 2). Blacks (8.4 versus $7.0 \%$ ) and Hispanics (5.0 versus $4.4 \%$ ) presented more emergently than Whites (56.6 versus $57.9 \%$ ) and other races (3.7 versus $3.8 \%$ ). By payer, only patients with private insurance presented less emergently (27.3 versus $31.9 \%)$. Patients with no comorbid conditions presented more emergently (64.6 versus $64.1 \%$ ), unlike those with one or more comorbid conditions.

Table 3 displays the trend in surgical resections over the 5-year period from 2003 to 2007 and the percentage of inhospital deaths in these cases. West Virginia shows greater inhospital deaths than the rest of the USA for each of the 5 years with an increasing trend, while the USA shows a decreasing trend in the deaths. There is a decreasing trend over the years in the LOS for both West Virginia and the USA, while total hospital charges show a steady increase for both during the period.

Table 4 displays the parameter estimates, standard errors, confidence intervals and significance of regression coefficients of West Virginia, emergency surgery and the covariates for LOS, hospital charges, and in-hospital death. The OLS regression showed that those undergoing emergency surgery spent $51.9 \%(\beta=0.40)$ more days in the hospital than those who underwent non-emergency resection. For West Virginia, LOS was $7.6 \%(\beta=0.07)$ higher than that of other states in the USA. Although those with two or more comorbid conditions had $33.6 \%(\beta=0.29)$ higher LOS compared to cases with no comorbidities, individual comorbid conditions had lesser impact, and presence of chronic obstructive pulmonary disease reduced the LOS by $1.3 \%(\beta=0.01)$.

Hospital charges for those that underwent emergency resection were $68.3 \%(\beta=0.52)$ higher than those who did not. However, the total charges in West Virginia were $33.5 \%(\beta=-0.29)$ lower than those of the other states in the USA. Presence of two or more comorbid 
conditions increased the total charges by $49.1 \%(\beta=0.40)$ compared to those with no comorbid conditions. Of the individual comorbidities, compared to patients with no hypertension, hypertensive patients had total hospital charges at $19.8 \%(\beta=0.18)$ times higher.

The odds of in-hospital death were 1.67 (95\% CI=1.42-1.98) times greater in West Virginia than those of the other states in the USA. Those that underwent emergency surgery had a nearly four times (OR 3.88; $95 \% \mathrm{CI}=3.74-4.03$ ) greater chance of in-hospital death than those who did not. As the number of comorbid conditions increased, the chances of dying in the hospital increased as well. However, among the most common chronic comorbid conditions, hypertensive patients were the only ones that showed increased odds (OR 1.26; $95 \% \mathrm{CI}=1.16-1.37)$ of dying in the hospital.

\section{Discussion}

This study compared the characteristics of those who underwent emergency versus nonemergency CRC resection surgery in West Virginia and the USA over a 5-year period from 2003 to 2007. It also examined the association between emergency CRC resection and outcomes of LOS, hospital charges, and in-hospital death. In contrast to a decrease in LOS over the years, there was an increase in hospital charges, in both the USA and West Virginia, which may have been a product of inflation or increase in the use of laparoscopic procedures $\left[{ }^{30}\right]$.

Patients who underwent emergency resections in the USA and West Virginia were associated with increased lengths of stay and greater hospital charges and had increased odds of inhospital death, all of which are consistent with previous studies. However, the odds of inhospital deaths were greater in West Virginia as compared to the USA over the 5-year period. It has been established that later stage at presentation is associated with presenting as an emergency condition for CRC $\left[{ }^{11}\right]$. However, proximal tumor location after controlling for stage has also been significantly associated with poorer mortality and survival as compared to sigmoid colon cancers $\left.{ }^{31}\right]$. The incidence rates for CRC in West Virginia have been known to increase with advancing age for cancers located in all anatomical subsite groups, but more substantially for proximal colon cancer than for descending and distal CRC especially in elderly men and women $\left[{ }^{32}\right]$. Further studies in West Virginia would need to establish the association of stage and tumor site at presentation with CRC outcomes.

Emergency CRC resection rates were lower in those with a higher number of comorbidities in both the USA and West Virginia. This could have been due to frequent contact with the healthcare system by sicker patients, which may have increased the probability of early detection of cancer [ $\left.{ }^{33}\right]$. It is also possible, as pointed out by Diggs and colleagues, that a sicker patient in whom resection could not be performed safely or those who elected not to undergo resection may not have been represented in the study population $\left[{ }^{13}\right]$. However, the regression models in both the USA and West Virginia also showed an increase in hospital burden with increasing number of comorbidities. Previous studies have established poorer outcomes in CRC with an increasing number of comorbidities [ $\left.{ }^{28},{ }^{34}\right]$. Our study showed that hypertension was one of the three most common chronic comorbid conditions and 
significantly affected the outcomes of surgery. There is no literature exploring the presence of hypertension and the outcomes of CRC surgery, and this can be an avenue for further research. Our results also showed that compared to non-diabetic patients, diabetics had increased LOS and total charges but decreased odds of inhospital deaths. This is in contrast to earlier studies that have found an increased risk of death in CRC patients with diabetes after controlling for demographic and treatment factors [ 27,35$]$. Future research must examine the influence of comorbid conditions along with emergency surgery and stage of disease on morbidity in CRC patients especially in states such as West Virginia where uncontrolled chronic diseases such as hypertension, hypercholesterolemia, and diabetes are highly prevalent $\left[{ }^{36}\right]$.

In spite of having higher LOS, total hospital charges in West Virginia were significantly lower than that of the other states. This could be due to variations by as much as $94 \%$ among states in the treatment of CRC as pointed about by Mushinski $\left[{ }^{37}\right]$. Her study of inhospital charges (US \$1,995) for CRC treatment reported that Illinois and California had the highest charges (33 and $29 \%$, respectively, above the US average) and Ohio, Kentucky, and Wisconsin had the lowest (each more than $20 \%$ below the norm).

As mentioned earlier, despite favorable legislation supporting insurance coverage, screening for CRC in West Virginia remains the lowest in the entire country [ ${ }^{18},{ }^{19}$ ]. Barriers to screening for CRC in West Virginia, besides failure of provider recommendation, lack of knowledge, and the belief that screening was not necessary without symptoms, include fear of cancer and the need for people to feel at risk for screening to occur $\left[{ }^{38}\right]$. A recent study of 24 primary care practices in New Jersey found that patients who are at increased CRC risk due to obesity, diabetes, and smoking were the least likely to be screened for CRC, to have received a physician recommendation for screening, and to adhere to physician recommendations, which therefore further highlight the need not only to raise patient awareness but to also check and disseminate adequate screening guidelines and awareness among primary care physicians $\left[{ }^{39}\right]$.

The findings in this study should be interpreted keeping in mind the various limitations associated with the data set used. This study used hospital discharge data, the quality of which may not be comparable to that of medical records. The number of patients that underwent emergency surgery in West Virginia may not have been large enough to make a comparison with non-emergency patients in the state. This study was limited in the number of years available to be included for analyses. Future studies may include additional years to reduce the difference in cohort sizes. The stage and site of the tumor at presentation, which may have influenced the outcomes, could not be determined from these data. It was also not possible to differentiate between admissions or readmissions due to improper management or primary admissions due to screening or diagnosis failures or cancer recurrence. West Virginia data on race and hospital characteristics were lacking, which may have influenced the outcome. The study population was limited to those undergoing resection procedures, and many patients presenting in emergency settings with CRC but did not undergo surgery, such as severe cases in which surgery would have been unsuccessful or the patient refused treatment, may not have been represented. 
Despite these limitations, the study is the first to highlight the importance of the significant burden of emergency CRC resections in the number one state for CRC incidence and mortality, West Virginia. Other states with high mortality rates may also face challenges related to increasing emergent hospital resections for CRC and consequently greater cost burden and poorer mortality outcomes. Thus, the study stresses the ongoing burden of emergency surgeries in many states around the nation and the need to increase awareness about CRC screening practices, especially in patients who are at increased risk of the disease.

\section{Acknowledgments}

The primary author was supported by a grant (1R24HS018622-01 PI: S. Madhavan) from the Agency of Healthcare Research and Quality during the conduct of this study.

\section{References}

1. Gellad ZF, Provenzale D. Colorectal cancer: national and international perspective on the burden of disease and public health impact. Gastroenterology. 2010; 138(6):2177-90. DOI: 10.1053/j.gastro. 2010.01.056 [PubMed: 20420954]

2. Hao Y, Jemal A, Zhang X, Ward EM. Trends in colorectal cancer incidence rates by age, race/ ethnicity, and indices of access to medical care, 1995-2004 (United States). Cancer Causes Control. 2009; 20(10):1855-63. DOI: 10.1007/s10552-009-9379-y [PubMed: 19543799]

3. Meissner HI, Breen N, Klabunde CN, Vernon SW. Patterns of colorectal cancer screening uptake among men and women in the United States. Cancer Epidemiol Biomarkers Prev. 2006; 15(2):38994. DOI: 10.1158/1055-9965.EPI-05-0678 [PubMed: 16492934]

4. Hoff G, Dominitz JA. Contrasting US and European approaches to colorectal cancer screening: which is best? Gut. 2010; 59(3):407-14. DOI: 10.1136/gut.2009.192948 [PubMed: 20207645]

5. American Cancer Society. Colorectal cancer facts \& figures 2011-2013. Atlanta: American Cancer Society; 2011.

6. Miller AB. Implementation of colon cancer screening: techniques, costs, and barriers. Gastroenterol Clin North Am. 2008; 37(1):83-95. DOI: 10.1016/j.gtc.2007.12.015 [PubMed: 18313541]

7. Redaelli A, Cranor CW, Okano GJ, Reese PR. Screening, prevention and socioeconomic costs associated with the treatment of colorectal cancer. Pharmacoeconomics. 2003; 21(17):1213-38. [PubMed: 14986736]

8. Cuffy M, Abir F, Audisio RA, Longo WE. Colorectal cancer presenting as surgical emergencies. Surg Oncol. 2004; 13(2-3):149-57. DOI: 10.1016/j.suronc.2004.08.002 [PubMed: 15572097]

9. Rabeneck L, Paszat LF, Li C. Risk factors for obstruction, perforation, or emergency admission at presentation in patients with colorectal cancer: a population-based study. Am J Gastroenterol. 2006; 101(5):1098-103. DOI: 10.1111/j.1572-0241.2006.00488.x [PubMed: 16573783]

10. Kim J, Mittal R, Konyalian V, King J, Stamos MJ, Kumar RR. Outcome analysis of patients undergoing colorectal resection for emergent and elective indications. Am Surg. 2007; 73(10): 991-3. [PubMed: 17983065]

11. Polednak AP. Inpatient hospital admission through an emergency department in relation to stage at diagnosis of colorectal cancer. Cancer Detect Prev. 2000; 24(3):283-9. [PubMed: 10975291]

12. Smothers L, Hynan L, Fleming J, Turnage R, Simmang C, Anthony T. Emergency surgery for colon carcinoma. Dis Colon Rectum. 2003; 46(1):24-30. DOI: 10.1097/01.DCR. 0000044719.17980.4C [PubMed: 12544518]

13. Diggs JC, Xu F, Diaz M, Cooper GS, Koroukian SM. Failure to screen: predictors and burden of emergency colorectal cancer resection. Am J Manag Care. 2007; 13(3):157-64. [PubMed: 17335359] 
14. McGillicuddy EA, Schuster KM, Davis KA, Longo WE. Factors predicting morbidity and mortality in emergency colorectal procedures in elderly patients. Arch Surg. 2009; 144(12):115762. DOI: 10.1001/archsurg.2009.203 [PubMed: 20026835]

15. Harris JR, Brown PK, Coughlin S, et al. The cancer prevention and control research network. Prev Chronic Dis. 2005; 2(1):A21. [PubMed: 15670474]

16. Lengerich EJ, Wyatt SW, Rubio A, et al. The Appalachia Cancer Network: cancer control research among a rural, medically under-served population. J Rural Health. 2004; 20(2):181-7. [PubMed: 15085633]

17. American Cancer Society (South Atlantic Division). South Atlantic Division cancer facts \& figures 2009. Atlanta: American Cancer Society; 2009.

18. The Appalachia Community Cancer Network. [Accessed 10/12, 2011] Colorectal cancer screening reimbursement and state legislation in Appalachia. http://www.accnweb.com/docs/2008/ PolicyBrief1.pdf

19. State Cancer Profiles. [Accessed 1/3, 2011] Screening and risk factors report. http:// statecancerprofiles.cancer.gov/risk/index.php? risk=09\&sex=0\&type=risk \&stateFIPS=00\&sortVariableName=default\&sortOrder $=$ default

20. American Cancer Society. Colorectal cancer facts \& figures 2008-2010. Atlanta: American Cancer Society; 2008.

21. Etzioni DA, Beart RW Jr, Madoff RD, Ault GT. Impact of the aging population on the demand for colorectal procedures. Dis Colon Rectum. 2009; 52(4):583-90. discussion 590-1. DOI: 10.1007/ DCR.0b013e3181a1d183 [PubMed: 19404056]

22. Hayanga AJ, Mukherjee D, Chang D, et al. Teaching hospital status and operative mortality in the United States: tipping point in the volume-outcome relationship following colon resections? Arch Surg. 2010; 145(4):346-50. DOI: 10.1001/archsurg.2010.24 [PubMed: 20404284]

23. Holt PR, Kozuch P, Mewar S. Colon cancer and the elderly: from screening to treatment in management of GI disease in the elderly. Best Pract Res Clin Gastroenterol. 2009; 23(6):889-907. DOI: 10.1016/j.bpg.2009.10.010 [PubMed: 19942166]

24. Qaseem A, Denberg TD, Hopkins RH, et al. Screening for colorectal cancer: a guidance statement from the American College of Physicians. Ann Intern Med. 2012; 156:378-86. [PubMed: 22393133]

25. Elixhauser A, Steiner C, Harris DR, Coffey RM. Comorbidity measures for use with administrative data. Med Care. 1998; 36(1):8-27. [PubMed: 9431328]

26. Giovannucci E. Insulin, insulin-like growth factors and colon cancer: a review of the evidence. J Nutr. 2001; 131(11 Suppl):3109S-20. [PubMed: 11694656]

27. Meyerhardt JA, Catalano PJ, Haller DG, et al. Impact of diabetes mellitus on outcomes in patients with colon cancer. J Clin Oncol. 2003; 21(3):433-40. [PubMed: 12560431]

28. Gross CP, Guo Z, McAvay GJ, Allore HG, Young M, Tinetti ME. Multimorbidity and survival in older persons with colorectal cancer. J Am Geriatr Soc. 2006; 54(12):1898-904. DOI: 10.1111/j. 1532-5415.2006.00973.x [PubMed: 17198496]

29. Halvorsen R, Palmquist R. The interpretation of dummy variables in semilogarithmic equations. Am Econ Rev. 1980; 70(3):474-5. http://econpapers.repec.org/RePEc:aea:aecrev:v:70:y:1980:i: 3:p:474-75.

30. Hernandez RA, de Verteuil RM, Fraser CM, Vale LD. Aberdeen Health Technology Assessment Group. Systematic review of economic evaluations of laparoscopic surgery for colorectal cancer. Colorectal Dis. 2008; 10(9):859-68. DOI: 10.1111/j.1463-1318.2008.01609.x [PubMed: 18624821]

31. Wray CM, Ziogas A, Hinojosa MW, Le H, Stamos MJ, Zell JA. Tumor subsite location within the colon is prognostic for survival after colon cancer diagnosis. Dis Colon Rectum. 2009; 52(8): 1359-66. DOI: 10.1007/DCR.0b013e3181a7b7de [PubMed: 19617745]

32. Jubelirer SJ, Wells JB, Emmett M, Broce M. Incidence of colorectal cancer in West Virginia from 1993-1999: an update by gender, age, subsite and stage. W V Med J. 2003; 99(5):182-6. [PubMed: 14959509] 
33. Heflin MT, Oddone EZ, Pieper CF, Burchett BM, Cohen HJ. The effect of comorbid illness on receipt of cancer screening by older people. J Am Geriatr Soc. 2002; 50(10):1651-8. [PubMed: 12366618]

34. Koroukian SM, Xu F, Bakaki PM, Diaz-Insua M, Towe TP, Owusu C. Comorbidities, functional limitations, and geriatric syndromes in relation to treatment and survival patterns among elders with colorectal cancer. J Gerontol A Biol Sci Med Sci. 2010; 65(3):322-9. DOI: 10.1093/gerona/ glp180 [PubMed: 20018824]

35. Coughlin SS, Calle EE, Teras LR, Petrelli J, Thun MJ. Diabetes mellitus as a predictor of cancer mortality in a large cohort of US adults. Am J Epidemiol. 2004; 159(12):1160-7. DOI: 10.1093/aje/kwh161 [PubMed: 15191933]

36. Ahluwalia IB, Tessaro I, Greenlund KJ, Ford ES. Factors associated with control of hypertension, hypercholesterolemia, and diabetes among low-income women in West Virginia. J Womens Health (Larchmt). 2010; 19(3):417-24. DOI: 10.1089/jwh.2009.1590 [PubMed: 20156080]

37. Mushinski M. Variation in in-hospital charges for colorectal cancer treatment. Stat Bull Metrop Insur Co. 1998; 79(1):19-27. [PubMed: 9476310]

38. Tessaro I, Mangone C, Parkar I, Pawar V. Knowledge, barriers, and predictors of colorectal cancer screening in an Appalachian church population. Prev Chronic Dis. 2006; 3(4):A123. [PubMed: 16978498]

39. Felsen CB, Piasecki A, Ferrante JM, Ohman-Strickland PA, Crabtree BF. Colorectal cancer screening among primary care patients: does risk affect screening behavior? J Community Health. 2011; 36(4):605-11. DOI: 10.1007/s10900-010-9348-0 [PubMed: 21203806] 


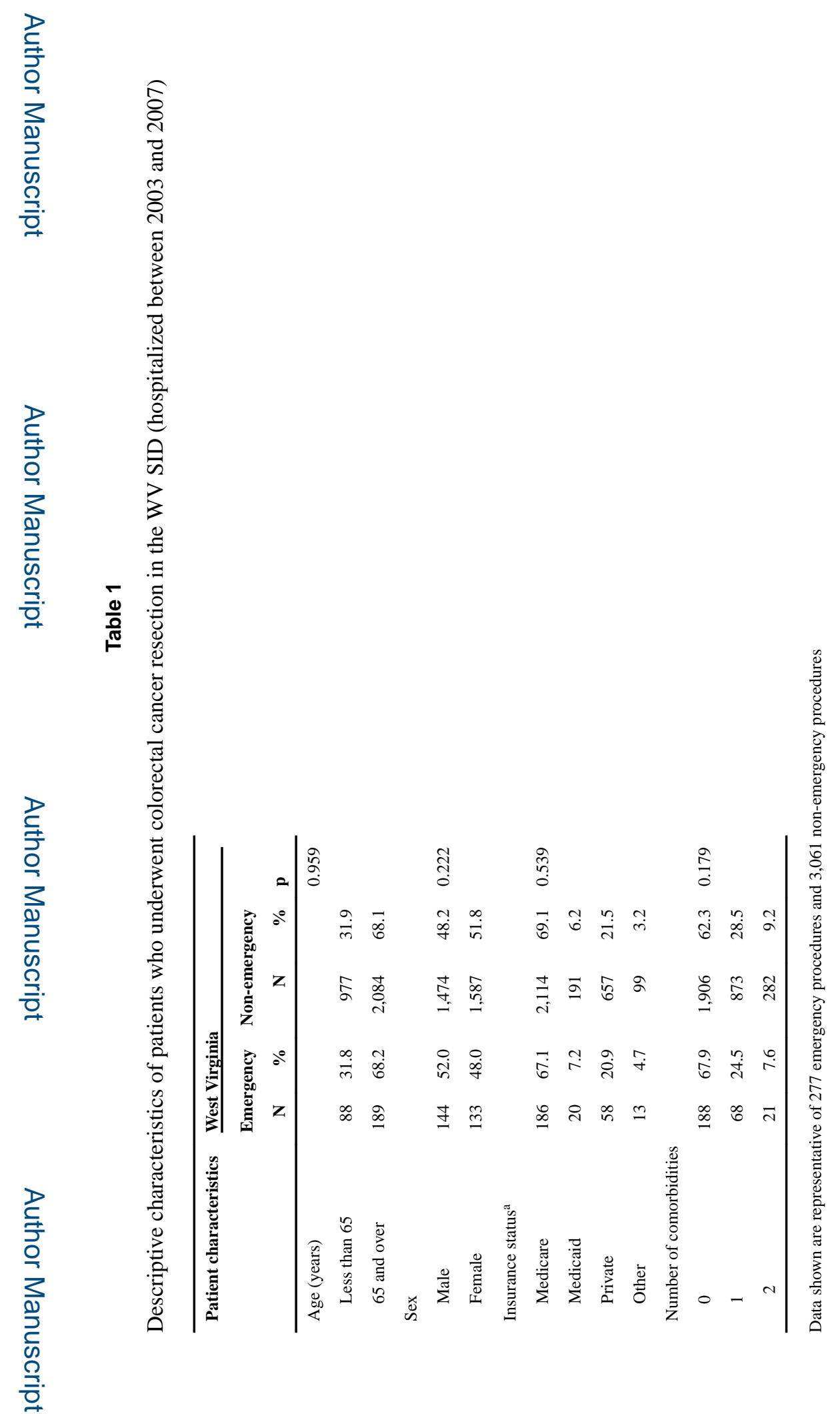




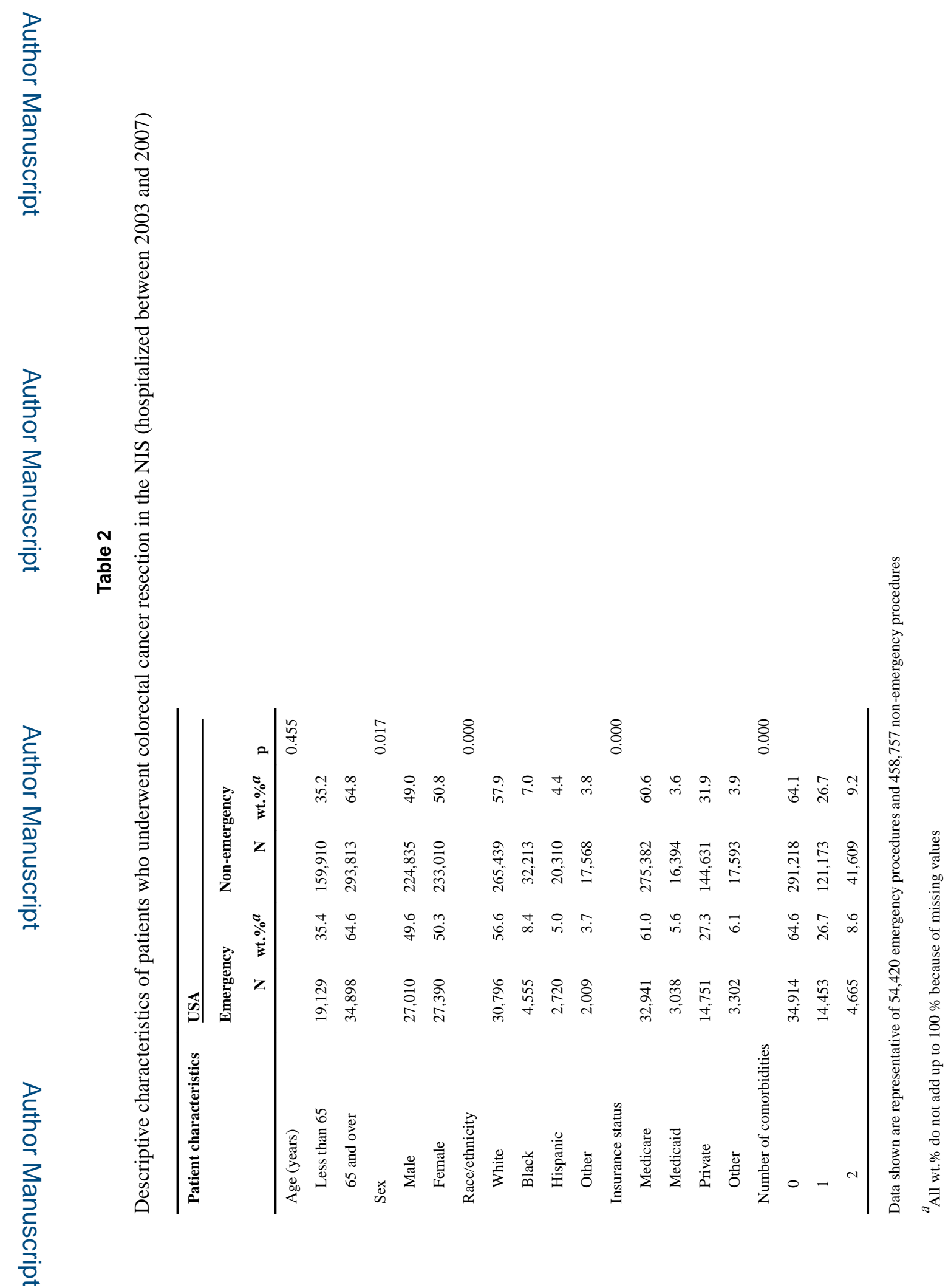

J Gastrointest Cancer: Author manuscript; available in PMC 2016 June 06. 


\section{롤 \\ }

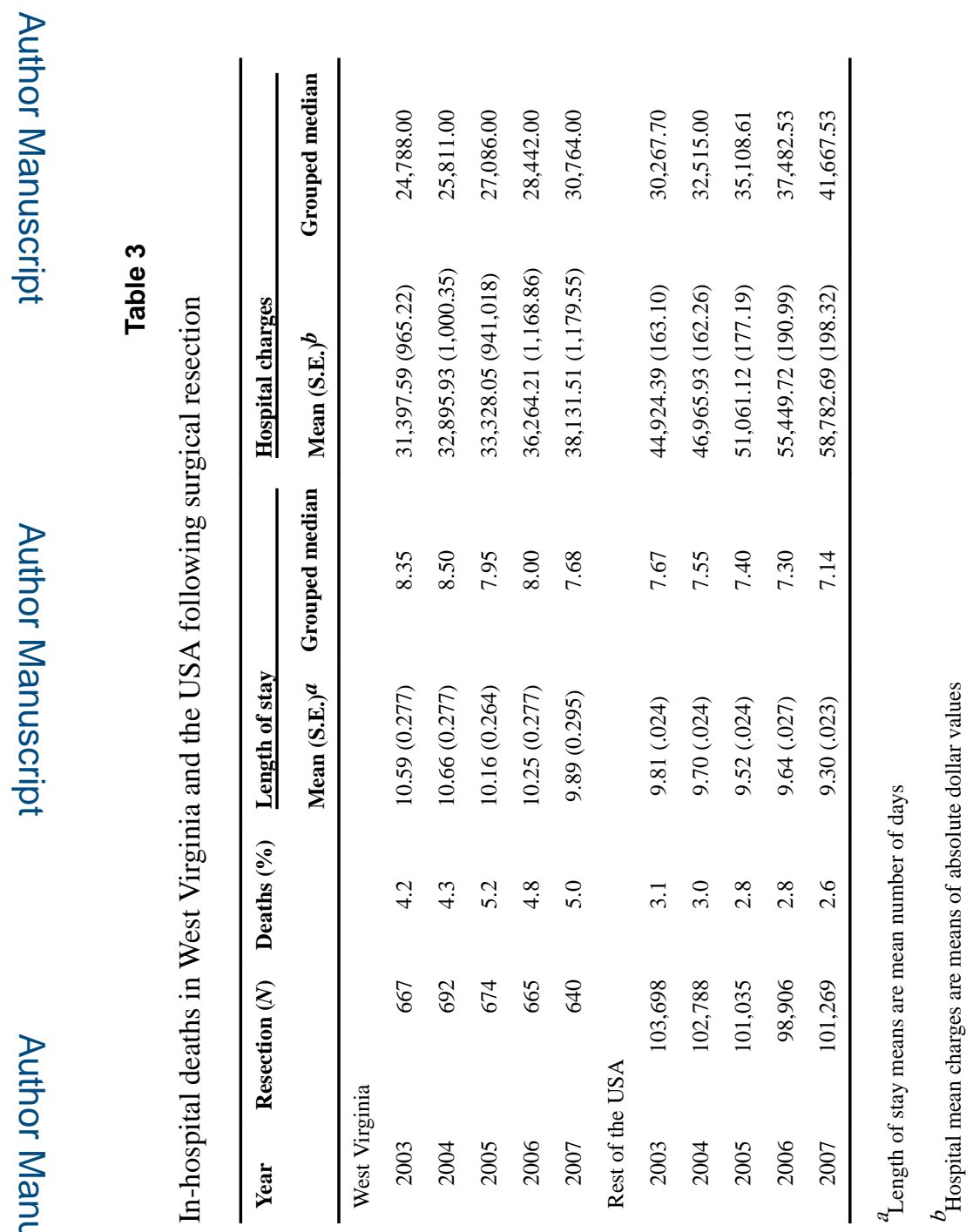




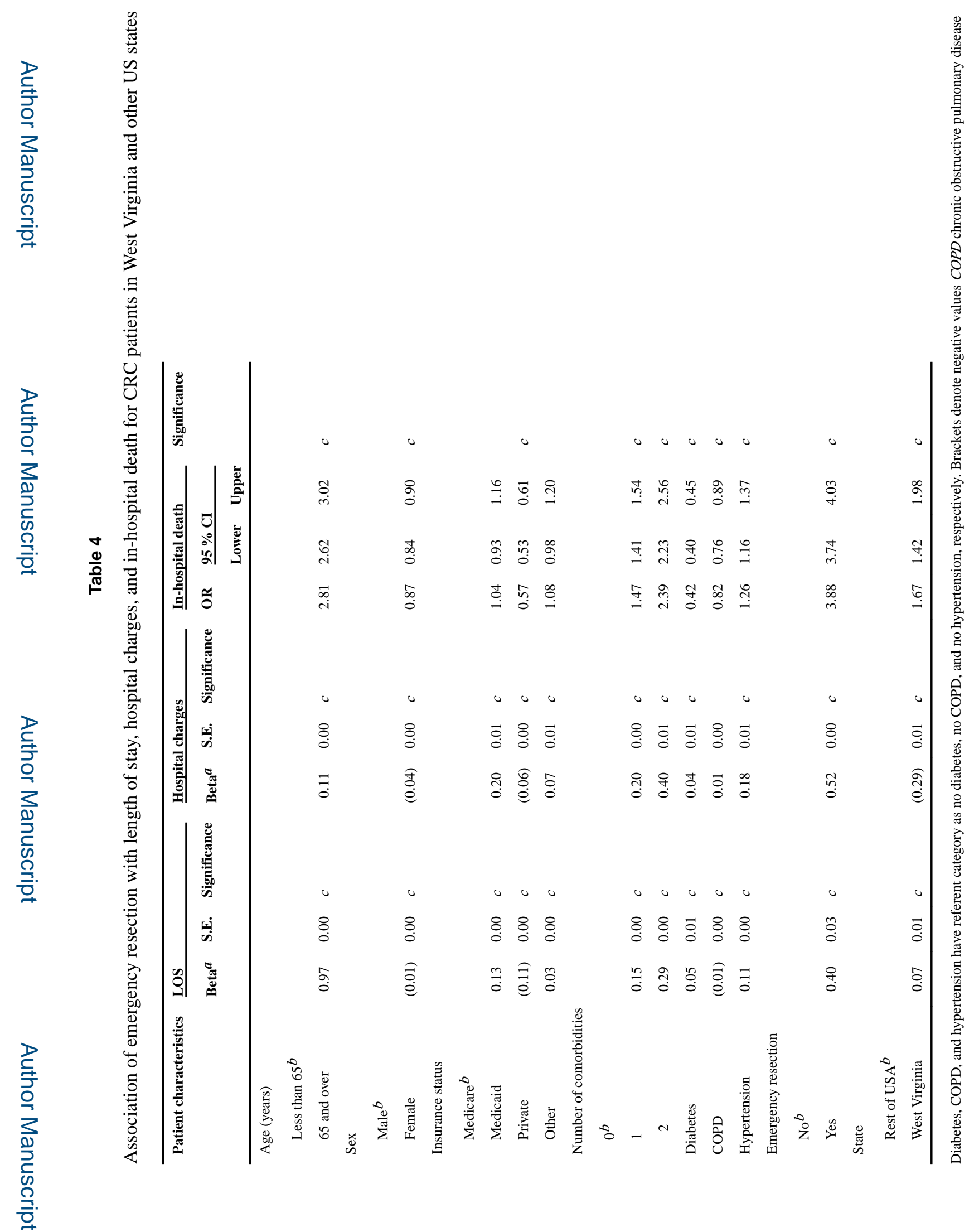

J Gastrointest Cancer: Author manuscript; available in PMC 2016 June 06. 


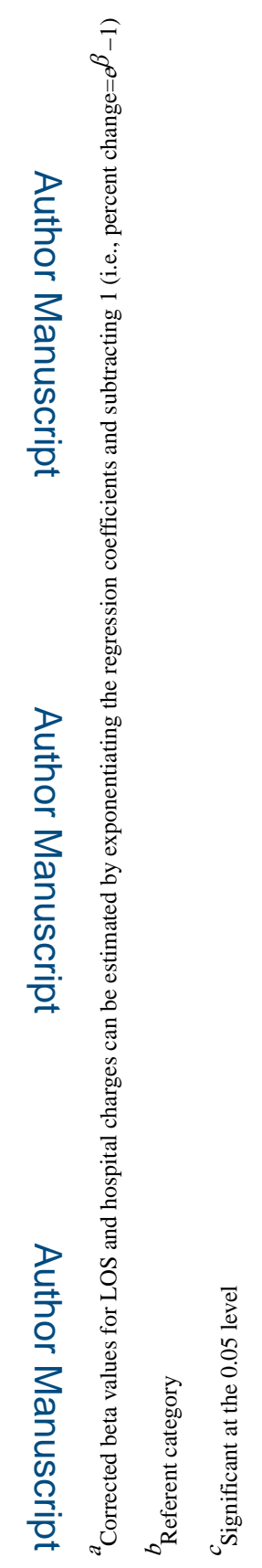

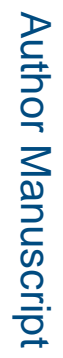

J Gastrointest Cancer: Author manuscript; available in PMC 2016 June 06. 